
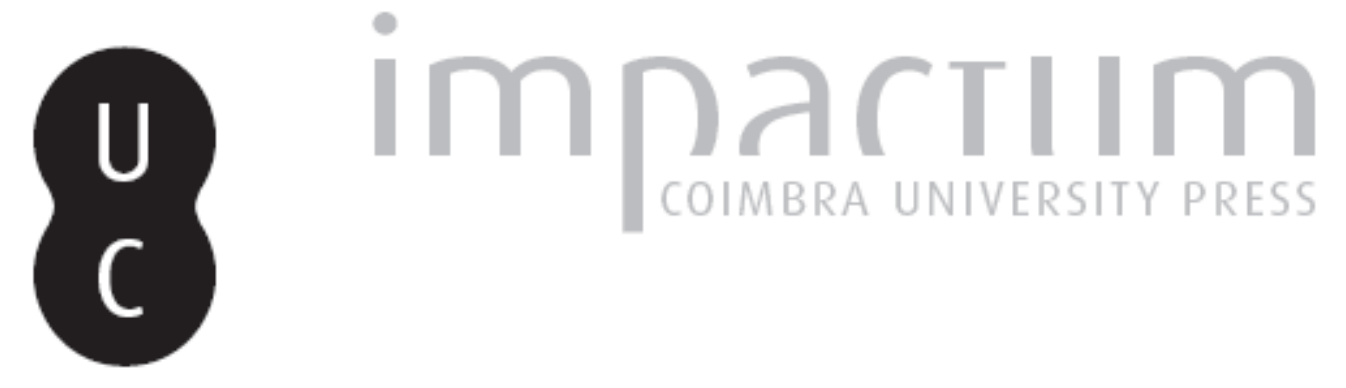

\title{
Maet, uma harmonia estética
}

\section{Autor(es): Lopes, Cristina}

Publicado por: Centro de História da Universidade de Lisboa

URL persistente:

URI:http://hdl.handle.net/10316.2/33027

DOI:

DOI:http://dx.doi.org/10.14195/0871-9527_22_16

Accessed : $\quad$ 26-Apr-2023 06:54:29

A navegação consulta e descarregamento dos títulos inseridos nas Bibliotecas Digitais UC Digitalis, UC Pombalina e UC Impactum, pressupõem a aceitação plena e sem reservas dos Termos e Condições de Uso destas Bibliotecas Digitais, disponíveis em https://digitalis.uc.pt/pt-pt/termos.

Conforme exposto nos referidos Termos e Condições de Uso, o descarregamento de títulos de acesso restrito requer uma licença válida de autorização devendo o utilizador aceder ao(s) documento(s) a partir de um endereço de IP da instituição detentora da supramencionada licença.

Ao utilizador é apenas permitido o descarregamento para uso pessoal, pelo que o emprego do(s) título(s) descarregado(s) para outro fim, designadamente comercial, carece de autorização do respetivo autor ou editor da obra.

Na medida em que todas as obras da UC Digitalis se encontram protegidas pelo Código do Direito de Autor e Direitos Conexos e demais legislação aplicável, toda a cópia, parcial ou total, deste documento, nos casos em que é legalmente admitida, deverá conter ou fazer-se acompanhar por este aviso.

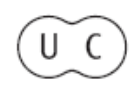



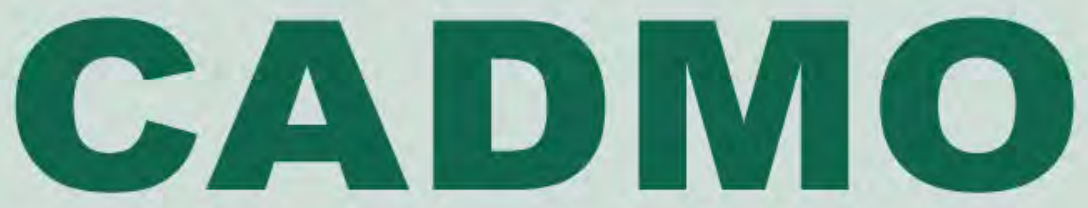

Revista de História Antiga

\author{
Centro de História \\ da Universidade de Lisboa
}

\title{
22
}

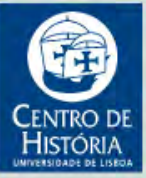

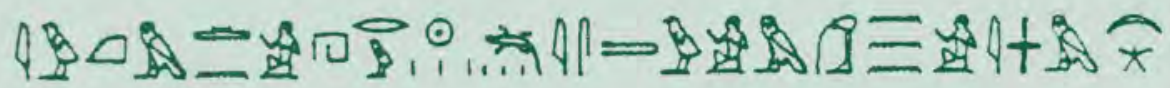

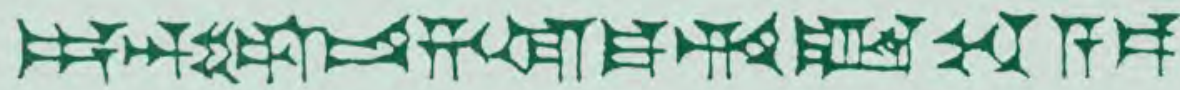
MHNIN AEI $\Delta \mathrm{E} \Theta \mathrm{EA} \Pi \mathrm{\Pi H} \Lambda \mathrm{HIA} \Delta \mathrm{E} \Omega$ 


\title{
MAET, UMA HARMONIA ESTÉTICA
}

CRISTINA LOPES

Faculdade de Belas Artes de Lisboa clopes99@gmail.com

\begin{abstract}
Resumo
O conceito de maet é sem dúvida um dos mais abrangentes e substanciais de toda a filosofia egípcia. Os atributos expressos simbolicamente têm uma humana explicação na personificação da deusa Maet como garante da ordem cósmica, enquanto harmonia, justiça e verdade. A maet é a noção de base do pensamento egípcio, funcionando como dogma donde emanam os mais elevados valores éticos, morais e sociais, materializados também na estética, e que permitiu a redação de textos sapienciais e conduziu a cultura do Egipto faraónico a um esplendor dos mais inebriantes até hoje forjado pela humanidade.
\end{abstract}

Palavras-chave: Maet; harmonia; estética.

\begin{abstract}
The concept of maet is undoubtedly one of the broadest and significant of the entire Egyptian philosophy. The attributes expressed symbolically, has an explanation in the personification of the goddess Maet and is a guarantee of cosmic order, while harmony, justice and truth. The concept of maet is the basis of Egyptian thought, working as a dogma from which emanate the highest ethical, moral and social values, also embodied in aesthetic and allowed the drafting of the Wisdom literature and culture of the pharaonic Egypt as a splendor of the most inebriating, wrought by humanity until today.
\end{abstract}

Key-words: Maet; harmony; aesthetics. 
O conceito de maet é holístico na medida em que, de certa forma, abrange todas as esferas da sociedade. A subordinação dos Egípcios (pelo menos os das classes letradas ou com funções dirigentes) em relação à maet torna-se sobretudo mais evidente a partir da $\mathrm{V}$ dinastia, num tempo em que se visava realizar a maet ${ }^{1}$. Apenas posteriormente tinham lugar todas as outras competências, abrangidas pelo poder da deusa.

O faraó, no topo da hierarquia humana, e como elemento de ligação com os deuses, tinha a obrigação de realizar a maet praticando rituais conhecidos desde o Império Antigo, e ele era o único ser qualificado para essa finalidade. O rei, oficiando como sacerdote, de pé ou ajoelhado, com um braço estendido, saudava diariamente o sol no momento do seu nascimento, com a "oferta de Maet», uma pequena estatueta que representava a deusa.

Nos relevos de alguns templos mais tardios encontra-se documentada a cerimónia do ofertório, como por exemplo em Edfu e em Dendera ${ }^{2}$, onde está o rei-sacerdote oficiante (que no caso destes templos são um rei ptolemaico ou um imperador romano), tal como os antigos faraós em importante ato litúrgico, a oferecer uma figurinha de Maet à divindade local. É precisamente em Dendera, espaço cultual de Hathor, que se encontra um texto mural com um longo hino a ser recitado no momento da dádiva. O ritual de $\mathrm{Amon}^{3}$ disponibilizou o documento capital que era a litania proferida aquando da entrega da estatueta à divindade, num extenso texto que reflete a abrangência, o significado e os deuses ligados a Maet que praticam e mantêm as normas maéticas sobre a terra ${ }^{4}$.

Geralmente a deusa é representada sentada, sobre uma perna, enquanto a outra está fletida e erguida, com o corpo coberto com um vestido justo, os braços abertos como que segurando umas grandes asas amplamente abertas, e com as formas harmoniosas com que habitualmente a iconografia egípcia nos acostumou, sendo que a sua marca distintiva é sem dúvida a pena de avestruz na cabeça, pena essa que por vezes substitui o seu nome na escrita hieroglífica ou o remata como determinativo ${ }^{5}$.

A instituição faraónica justifica-se na medida em que é uma religião que promove a libertação de energias cosmogónicas e salvadoras ${ }^{6}$. Maet seria então a salvaguarda contra os opositores divinos, como é aliás atestado em textos como o que consta no Papiro Chester Beatty IV ${ }^{7}$, e onde a pendular deusa revela um aspeto mais ameaçador e inusitado para defender o deus Amon. 
Segundo o pentâmero conceptual de Jan Assmann, são considerados os âmbitos de ação do sagrado, o cosmos, o Estado, a sociedade e o indivíduo. Assim constatamos que o senhor das Duas Terras para aplicar a maet dispunha de um expedito corpo de funcionários ${ }^{8}$, de entre os quais se destacavam os que estavam ligados à justiça, que usavam como símbolo identificador uma pequena efígie de Maet, geralmente de lápislazúli, pendurado ao peito. Os juízes eram considerados sacerdotes da deusa e deviam praticar a maet no exercício das suas funções, enquanto o tjati (vizir) deveria falar usando os elevados preceitos de Maet, dando vivo exemplo dos mesmos.

Quanto aos deuses, vários eram chamados «senhores de maet», isto é, prodigalizadores de justiça, verdade e harmonia, e entre eles se inclui o deus solar Ré, considerado como pai de Maet. Por outro lado, o demiurgo Ptah, que tutelava o panteão menfita, foi muitas vezes representado sobre um pedestal com a forma do hieróglifo de Maet. Amon-Ré, consagrando

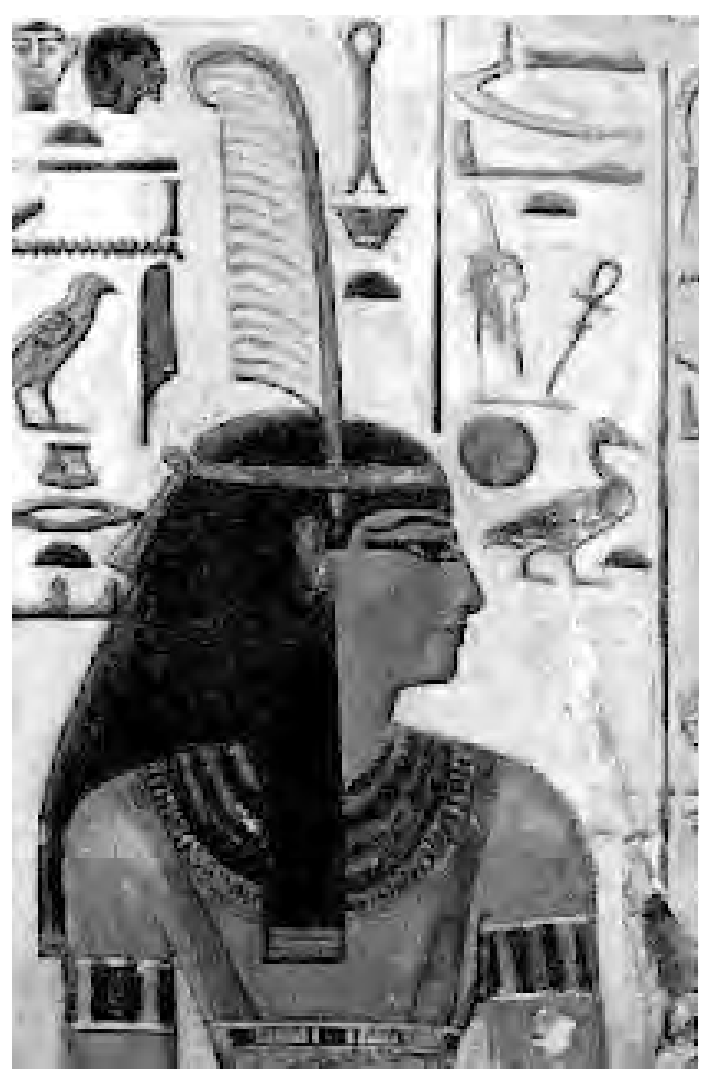

A deusa Maet, bem reconhecida pela sua pluma e pelo texto hieroglífico que a identifica como filha de Ré. A inscrição apresenta ainda a deusa como «dama que está sobre a terra do silêncio", ou seja, a necrópole (Museu de Florença). 
a fonte da vida e de toda a ordem, era também "campeão de justiça», renovando continuamente a luz na sua pujança sincrética com o deus solar, no seu significado cósmico, social e moral de ritmo do universo, de justo governo, harmoniosas relações humanas, lei, justiça e verdade. O deus Tot de Hermópolis podia ser visto como o esposo de Maet por ser o «símbolo divino da precisão e exactidão».

A estética enquanto observa a arte "olha-a» como representação formal ou moral de conceitos que estão na base do desenvolvimento da obra de arte. Numa perspetiva histórica, a arte e a moral vivem em boa harmonia. Ora como a estética etimologicamente significa isthesis em grego, e que por sua vez significa sensibilidade, que pressupõe por seu turno a sensibilidade enquanto filosofia da arte e um outro que se relaciona com a afectividade no sentido psicológico e portanto mais subtil, eis um caminho para apreciar a maet.

Parece de alguma forma que o critério da estética e do misticismo é o êxtase, assim também a arte autêntica se impõe por uma procura feita num espirito de religiosidade. Tal como o verdadeiro é o local onde se encontram todos os valores, o sagrado é o fim, o ideal transcendente, para o qual todos tendem naturalmente. A arte é pois um patamar na ascensão para o absoluto tido como forma de encarnar o ideal no real, ou o divino no homem.

A estética em Maet está, como não poderia deixar de ser, muito relacionada com os conceitos intrínsecos que lhe são inerentes. É uma estética ao mesmo tempo objetiva e que permanece sensual e sensualista. Finalmente é uma estética hierárquica, que corresponde directamente na hierarquia terrena ao conceito que lhe está subjacente no qual o belo e o bem se identificam. Fazendo uma análise platónica ${ }^{9}$ da estética em Maet, teríamos então três tipos de beleza hierarquizados:

- A beleza do corpo, enquanto pertencente à beleza inferior.

- A beleza da alma que é virtude e beleza verdadeira, que encontramos em obras como o Fedro. Associado à pureza e à beleza da alma em todas as coisas, a medida e a proporção constituem a beleza e a virtude. Maet representa precisamente a medida de todas as coisas, desde a justiça à integração da alma do morto na ordem universal aquando do julgamento final.

- E para os sábios há a beleza em si, em que beleza suprema está ligada à ideia do verdadeiro e do bem. Ou seja, o belo age reciprocamente sobre as ideias. A justiça não é só um acordo, uma identidade entre dois elementos, mas antes uma harmonia que tudo une. A verdade é que o curso solar, com a vitória da luz sobre as trevas e da vida e movimento sobre a 
morte, é cena arquetípica do bem-estar individual e social. O deus do Sol triunfa no quadro de uma ordem jurídica bela que ele próprio ergue e impõe. Neste breve texto foram abordados alguns dos aspetos que se relacionam com a estética, a filosofia da arte e com o conceito de maet, personificado na deusa Maet. Este cruzamento de perspetivas pode ser um ponto de partida para um relacionamento destes campos do saber aparentemente distantes, mas que a certos níveis se cruzam e interrelacionam. No século XXI, numa sociedade globalizada, o valor da comunicação e a relação das diferentes abordagens e disciplinas é certamente gratificante para todas as partes envolvidas e potencia um frutuoso diálogo.

\section{Notas}

(1) ASSMANN, Maât, I’Égypte pharaonique et l'idée de justice sociale, pp. 89-92.

(2) WILKINSON, The Complete Temples of Ancient Egypt, pp. 155 e 163; BAINES e MÁLEK, Egipto. Deuses, templos e faraós, pp. 91-92. Saliente-se que Shaw e Nicholson fazem notar que apesar da figura de Maet ser largamente representada em templos de outras divindades, somente alguns templos dedicados à própria deusa sobrevivem, incluindo uma pequena estrutura no recinto de Montu em Karnak, não apresentando outro exemplo (I. SHAW e P. NICHOLSON, British Museum Dictionary of Ancient Egypt, p. 186).

(3) Este é o «documento capital», aquando do ritual do ofertório; ver ARAÚJO, «Maet», Dicionário do Antigo Egipto, pp. 533-534 (aqui se encontra um extenso texto, com a transcrição essencial segundo a tradução elaborada por François Daumas).

(4) Manter os preceitos e rituais tinha como função a manutenção da harmonia, ordem, justiça e beleza. Assim, e muito naturalmente, o faraó ou o oficiante para tal designado, ao cumprir as regras e os ritos contribuía para a manutenção de maet, numa simbiótica relação de «dar Maet para receber Maet»; ver ARAÚJO, «Maet», Dicionário do Antigo Egipto, p. 533.

(5) Frequentemente representada nos baixos-relevos dos templos ou nas pinturas dos túmulos, na estatuária, nas ilustrações do «Livro dos Mortos», onde o seu nome e figura surgem com abundância, é garante de sobrevivência e imortalidade; ver ARAÚJO, «Maet», Dicionário do Antigo Egipto, p. 530.

(6) A hierarquia do Egipto faraónico afastava o caos com o cumprimento dos preceitos maéticos, como podemos perceber em TEETER, The Presentation of Maât. Ritual and Legitimacy in Ancient Egypt, p. 2; e em ARAÚJO, «Maet», Dicionário do Antigo Egipto, p. 530.

(7) Podemos constatar num breve passo pertencente ao deus Amon: «Maet é a tua mãe, Amon. Ela é tua, ela é única. Ela saiu de ti. Ela entra em furor para consumir aqueles que te atacam.» Eis pois a preponderante deusa Maet como filha e mãe num eterno reinventar do cosmos renascido.

(8) Estas concepções estão presentes tendo em conta que «a instituição faraónica é portanto mais uma religião do que um Estado: porque a libertação de energias cosmogónicas e salvadoras faz-se por adoração e por troca comunicativa. O Estado é a gestão da salvação. É a união perfeita da salvação e da dominação»; ver ASSMANN, Maat, L'Égypt pharaonique et lídée de justice sociale, p. 138.

(9) Num certo sentido trata-se da aparência equilibrada e harmoniosa do exterior em que existe a ênfase do conceito do belo do ponto de vista do bem, não se trata apenas do bem moral - é sempre a tese do vantajoso, em suma, aquela que Platão sempre defenderá, a Kalocagatia. 


\section{Bibliografia consultada}

Cyril ALDRED, Egyptian art in the days of the pharaohs, 3100-320 BC. Londres: Thames and Hudson, 1985.

Luís Manuel de ARAÚJO, Antiguidades Egípcias, I, Museu Nacional de Arqueologia, Lisboa: Instituto Português de Museus, 1993.

Luís Manuel de ARAÚJO, «Maet», em Dicionário do Antigo Egipto, Lisboa: Editorial Caminho, 2001, pp. 524-536.

Luís Manuel de ARAÚJO, Arte Egípcia. Colecção Calouste Gulbenkian, Museu Calouste Gulbenkian, Lisboa: Fundação Calouste Gulbenkian, 2006.

Jan ASSMANN, The Search for God in Ancient Egypt, Londres: Cornell University Press, 1984.

Jan ASSMANN, Maât, l'Égypte pharaonique et l'idée de justice sociale, Paris: Éditions La Maison de Vie, 1999, pp. 89-92.

Jan ASSMANN, The Mind of Egypt: History and meaning in the time of the pharaohs, Cambridge, Massachusetts, Londres: Harvard University Press, 2002.

John BAINES e Jaromír MÁLEK, Egipto. Deuses, templos e faraós, Lisboa: Círculo de Leitores, 1991.

Raymond BAYER, História da Estética. Lisboa: Editorial Estampa, 1978.

Terry EAGLETON, The Ideology of the Aesthetic, Londres: T. J. Press Ltd, 1990.

Susan FEAGIN e Patrick MAYNARD (ed.), Aesthetics, Oxford: Oxford University Press, 1997.

George HART, A Dictionary of Egyptian Gods and Goddesses, Londres, Nova lorque: Routledge \& Kegan Paul, 1986.

Denis HUISMAN, A Estética. Lisboa: Edições 70, 1994.

Jean LECLANT (dir.), Le Monde Égyptien. Les Pharaons, três volumes, Col. L'Univers des Formes, Paris: Éditions Gallimard, 1978-1980.

Jerrold LEVINSON, The Pleasures of Aesthetics, Londres: Cornell University Press, 1996.

Colin LYAS, Aesthetics, Londres: UCL Press, 1997.

José das Candelas SALES, Estudos de Egiptologia, Lisboa: Livros Horizonte, 2007.

José das Candelas SALES, As Divindades Egípcias: uma chave para a compreensão do Egipto Antigo, Lisboa: Editorial Estampa, 1999.

José das Candelas SALES, Poder e iconografia no antigo Egipto, Lisboa: Livros Horizonte, 2008.

Ian SHAW e Paul NICHOLSON, The British Museum Dictionary of Ancient Egypt, Londres: British Museum Press, 1995.

Emily TEETER, The Presentation of Maat. Ritual and Legitimacy in Ancient Egypt, SAOC 57, Chicago: The Oriental Institute of the University of Chicago, 1997.

Richard H. WILKINSON, The Complete Temples of Ancient Egypt, Londres: Thames and Hudson, 1994. 